\title{
Plastic Optical Fiber pH Sensor Using a Sol-Gel Sensing Matrix
}

\author{
Luigi Rovati ${ }^{1}$, Paola Fabbri ${ }^{2}$, Luca Ferrari ${ }^{1}$ and Francesco Pilati ${ }^{2}$ \\ ${ }^{1}$ Department of Information Engineering, \\ 2Department of Materials and Environmental Engineering, \\ University of Modena and Reggio Emilia \\ Italy
}

\section{Introduction}

Because it is the most ubiquitous species encountered in chemical reactions, hydrogen ion occupies a very special place in chemistry and biology, most of the chemical and biological processes being dependent on its activity. From the analytical point of view, the abundance of hydrogen ions is quantified in terms of $\mathrm{pH}$, the negative logarithm of its activity. Its importance is evident by considering that, if the $\mathrm{pH}$ of the human blood changes as little as $0.03 \mathrm{pH}$ units or less, the functioning of the body will be greatly impaired; also, brain $\mathrm{pH}$ decreases from normal $\mathrm{pH}$ of 7.4 to a $\mathrm{pH}$ of 6.75 during the brain insult and a continuous monitoring system would be beneficial in the treatment of comatose neurosurgical patients and those who have suffered traumatic brain injury, ischemic brain insult and so forth (Zauner, 1995). Furthermore, the kind of animals and plants living in lakes, rivers and oceans depends on $\mathrm{pH}$ values, as well as $\mathrm{pH}$ of soil affects the livability of plants. For this reason, the use of $\mathrm{pH}$ sensors is widely diffused in various fields to monitor chemical and biological processes and it is finding an increasing number of applications in medicine, biomedicine, industry and environmental monitoring.

The earliest methods of $\mathrm{pH}$ measurement fall roughly into four categories: indicator reagents, $\mathrm{pH}$ test strips, amperometric or potentiometric devices. Since a long time, the glass electrode $\mathrm{pH}$ sensor has been the most popular due to its ideal Nernstian response, independent of redox interferences, and because of its high selectivity for hydrogen ions in a solution, short balancing time of electrical potential, reliability and high reproducibility, and long lifetime. For these reasons, it is still considered to be the standard measuring method for the $\mathrm{pH}$ measurements.

However, glass electrodes have several drawbacks for many applications. Firstly, they exhibit a sluggish response and are difficult to miniaturize. Moreover they can generate electromagnetic interferences with other devices and cannot be used in food or in vivo applications due to their brittle nature. For these reasons, there is increasing need for alternative $\mathrm{pH}$ sensors and, in this respect, optical methods offer many advantages over the common glass electrode or other electrochemical devices. Among these, optical fiber colorimetric $\mathrm{pH}$ sensors monitoring the change in the optical response of proton-sensitive indicators are the most popular systems. Other $\mathrm{pH}$-sensing devices, based on different 
$\mathrm{pH}$-related properties, have also been proposed; they exploit mass-changing in $\mathrm{pH}$ responsive hydrogel (Ruan, 2003), $\mathrm{pH}$-sensitive changes of refractive-index in polymers (Zamarreno, 2010), $\mathrm{pH}$ sensing based on the interferometric response of nanofilms built from layer-by-layer electrostatic self-assembly of polyelectrolytes (Goicoechea, 2009), pH sensors based on conducting polymers (including polypirrole, polyaniline, etc.) (Talaie, 2000), ultrasensitive microcantilever structures (Bashir, 2002; Fritz, 2000), to mention only someone. However, these devices suffer from various drawbacks such as instability or drift or their use is not straightforward or are too expensive to be mass-produced at industrial level.

For a more detailed discussion about $\mathrm{pH}$ sensors, one may refer to several reviews appeared in the last decade (Lin, 2000; Wolfbeis, 2004; Yuqing, 2005; Korostynska, 2007; Baldini, 2008; Wolfbeis, 2008; McDonagh, 2008).

As said above, optical fiber methods are the most interesting alternative to the glass electrode for $\mathrm{pH}$ as they enable optical spectroscopy to be performed on sites inaccessible to conventional spectroscopy and over long distances. This is particularly interesting in medicine where the high degree of miniaturization of optical fibers, their considerable geometrical versatility, and their extreme handiness enable unique performances in invasive applications. With respect to glass electrode $\mathrm{pH}$ sensors, optical fiber methods take also advantage of the immunity to electromagnetic interferences, and from the absence of electrical contacts that make them useful also in the case of non-invasive applications. For these reasons, optical fiber sensors are in continuous development and offer to the physicians efficient tools for prompt and reliable diagnosis, in particular when an in-vivo continuous monitoring has to be carried out (Baldini, 2008).

The basic concept of the optical fiber methods of $\mathrm{pH}$ measurements relies on the fact that the incident beam of light is passed through a light guide to the active end of the optical fiber where it interacts with a chemical indicator, which alters the beam's intensity, usually by absorption or fluorescence, of the modified optical signal which is guided back to the detector. In this way, remote sensing can be achieved since the optical signal can be carried over long distances.

The indicator is usually an organic dye able to change its color over a given $\mathrm{pH}$ range (typically 3-4 $\mathrm{pH}$ units centered at the $\mathrm{pKa}$ of a given indicator) and is generally confined to the surface of the optical fiber or immobilized in an adjacent space according to various possible configurations of the sensing element (Lin, 1997; McDonagh, 2008).

In order to record reliable $\mathrm{pH}$ values, the hydrogen ion concentration must equilibrate between the bulk of the sample and the space where the indicator is confined, and the sensor response in terms of precision, sensitivity, stability and response-time will therefore depend on the conditions existing within this space.

The most used method exploited to prepare an optical fiber responsive to $\mathrm{pH}$ changes is the immobilization of $\mathrm{pH}$ indicators in/on a suitable material. This is a key step that will largely influence the characteristics of the $\mathrm{pH}$ sensor.

Photopolymerization (Barnard, 1991; Bronk, 1994; Ferguson, 1997; Healey, 1997; Song, 1997) and sol-gel chemistry (Lin, 1997 and 2000; McDonagh, 2008) have been the mainly exploited reactions, and adsorption, covalent binding and entrapment are the most widely used approaches to immobilize indicator dyes. 
In the adsorption method, a pH indicator is adsorbed, physically or chemically, on a solid support attached to the optical fiber; it is relatively simple, but the amount of the adsorbed indicator may be small, resulting in a weak signal, and the indicator may leach out, resulting in a $\mathrm{pH}$ response that changes with time. Commercial ion-exchange resins, sulphonated polystyrene (Igarashi, 1994) and polyelectrolyte containing silica (Shi, 1997) have been proposed, among the other, for electrostatic immobilization, while hydrophobic organic products (polymers or organically modified alkoxysilanes) have been used to improve hydrophobic chemical adsorption of indicators (Korostynska, 2007; Kowada, 2005; Wu, 2006).

Adsorption of the indicator may be slow in non-porous monolithic solids and in solids with random microporosity, and the development of mesoporosity, having large and controlled open pores (Cagnol, 2004; Grosso, 2004), may result in a shorter response time of the $\mathrm{pH}$ sensor (enhanced diffusion and accessibility for protons and therefore faster equilibration) and a larger amount of $\mathrm{pH}$ indicator to be immobilized. However indicator leaching may also become a more relevant problem.

The covalent method can overcome leaching problems as the $\mathrm{pH}$ indicator is strongly bound to the solid substrate (Baldini, 2008; Barnard, 1991; Bronk, 1994; Ferguson, 1997; Healey, 1997; Song, 1997). However, the immobilization by covalent attachment requires a previous surface modification of the optical fibers and the control of the surface reaction of the modified substrate with a suitable indicator. The resulting procedure is often complicated and time consuming and may lead to loss of indicator sensitivity or result in poor fluorescent properties (Bacci, 1991; Lobnik, 1998). In general, this leads to a costly technology unsuitable for the preparation of mass-produced disposable devices.

In the entrapment method, the $\mathrm{pH}$ indicator is entrapped in a substrate, often starting from a polymer solution or a polymerizable liquid. The method is relatively easy, and a suitable choice of the indicator/polymer pair can strongly reduce or completely overcome the problem of indicator leaching. In addition, polymers present the advantage to be less brittle than inorganic glasses, and a suitable design of the molecular architecture can lead to a good balance of hydrophobicity and water swelling. This could allow combining a faster penetration of water and ions with a minimized indicator leaching. Various polymers have been used for entrapment of $\mathrm{pH}$ indicators by exploiting either their thermodynamic affinity or by covalent binding of $\mathrm{pH}$ indicators (Korostynska, 2007; McDonagh, 2008).

Combination of adsorption and entrapment methods is expected to occur in polymercontaining organic-inorganic hybrid materials, where highly interpenetrated organic and inorganic nanosized domains are formed during the sol-gel process. This could result in improved sensors, when, in addition to the control of water swelling by a suitable polymer choice, the presence of an extended interfacial surface between organic and inorganic domains, can favor the physical adsorption of the indicator. This can allow to optimize the mobility of the hydrogen ions, from the sample into the sensing element, resulting in a reduced response time, and to minimize indicator leaching.

Optical fiber $\mathrm{pH}$ sensors can also be prepared in the absence of indicators by exploiting the change of color as a function of $\mathrm{pH}$ of some conductive polymers such as polyanilines (Pringsheim, 1997; Sotomayor, 1997; Grummt, 1997) and polypirrole (de Marcos, 1996). Even though they present some intrinsic advantages, such as simple fabrication and 
measurements in the near-IR region, they suffer from shortcomings like long response time (slow diffusion of water and hydrogen ions into the glassy polymers), interference from other ions, oxidation by oxidizing agents and the need for pre/reconditioning before each measurement.

In the last two decades sol-gel chemistry has become one of the most widely used method for the development of optical fiber $\mathrm{pH}$ sensors due to its versatility and to the attractive optical properties of inorganic sol-gel materials (Lin, 1997, 2000; Wolfbeis, 2004, 2008; McDonagh, 2008). Indeed, either inorganic glasses or organic-inorganic hybrid materials can be easily obtained under mild conditions $\left(\mathrm{T}<100^{\circ} \mathrm{C}\right)$ starting from a low-viscosity solution containing metal alkoxides alone or mixed with organically modified alkoxysilanes or with suitable polymers. Sol-gel process key parameters like reactant formulation, catalyst, water content and reaction temperature, can be exploited to produce a large variety of materials whose properties can be finely adjusted to tailor the physicochemical properties of the final solid in order to optimize sensor performances (Wen, 1996; Cagnol, 2004; Grosso, 2004; Estella, 2007).

Various sol-gel material configurations, like monoliths, thin films, capillaries and droplets including miniaturized configurations, have been proposed to generate the sensing element at the optical fiber tip (Lin, 1997; McDonagh, 2008).

Alkoxysilanes are most frequently used as precursors of inorganic phases, and the resulting inorganic silica glasses are porous matrices, that can be characterized by tailored porosity (Wen, 1996; Cagnol, 2004; Grosso, 2004; Estella, 2007). Compared with pure organic polymers, sol-gel inorganic glasses can offer some advantages: higher stability, optical transparency down to $250 \mathrm{~nm}$, feasibility of direct coating on glass and silica fibers. However, they also may suffer from some shortcomings, and in particular, slow response to pH changes (typically several tens of seconds) (Lin, 1997; Ben-David, 1997; Seki, 2007), indicator leaching, difficult adhesion to plastic optical fibers.

Sol-gel materials derived from organically modified alkoxysilane (Ormosil) can be prepared under the same reaction conditions used for the preparation of all inorganic sol-gel glasses. The resulting material can have a better surface interaction with organic indicators reducing the shortcomings deriving from leaching (Kowada, 2005; Wu, 2006).

The inclusion of suitable organic polymers in the initial solution with alkoxysilanes leads to the formation of silica-based hybrid materials consisting of highly interpenetrated organic and inorganic domains. A suitable choice of the organic polymers will result in the formation of organic domains that can allow to immobilize higher amounts of indicator and to optimize indicator performances (Cjlakovic, 2002; Aubonnet, 2003) versus water adsorption, while preserving good transparency. As it will be discussed in the following, this can result in fast and reliable cheap sensors.

A lot of progress, improvement and innovation have been made in the field of optical fiber sensors in the last two decades, however notwithstanding the high number of optical fiber chemical and biochemical sensors described in the literature, only a few have reached the market, and the goal of mass production and commercialization of optical fiber $\mathrm{pH}$ sensors has not really been accomplished, and research development and application of optical fiber $\mathrm{pH}$ sensors is still very challenging and demanding interdisciplinary field. To reach this goal issues such as low cost, user-friendliness, sensitivity, robustness, long-term stability and shelf lifetime of the sensors have to be addressed adequately. 
Within this context, this paper aims at illustrating a facile method to develop plastic optical fiber $\mathrm{pH}$ sensors with a tip-based sensing element prepared by a sol-gel process and consisting of phenol red indicator entrapped in a PEO-silica organic-inorganic hybrid material.

\section{Principle, theory, design of the POE pH sensor}

Current trends in optical sensors, such as miniaturization, flexibility and enhanced sensitivity, are indicating a new chemical route for the development of advanced multifunctional materials for optical applications. Those chemical technologies, which can be more easily customized and allows the inclusion of multiple functionalities within a unique preparation step, are bound to be progressively more and more applied to the preparation of optical materials.

In this perspective, the sol-gel technology certainly represents one of the most promising chemical strategies, thanks to numerous advantages mainly related to simplicity and mild operative conditions. It enables creating a glass-like porous structure at room temperature by a two-step acid or base catalyzed reaction involving hydrolysis and condensation, starting with metal alkoxides $\mathrm{M}(\mathrm{OR})_{4}$, which transforms into a rigid three-dimensional metal-oxide network (Brinker, 1990). The sol-gel process has been proved to be flexible enough for an efficient incorporation of organic polymer chains that can behave as flexible links between the metal-oxide domains in the inorganic network, in particular when they are bearing reactive groups that can be involved in the hydrolysis-condensation reactions. The resulting materials are known as organic-inorganic hybrids (Schmidt, 2000), also commonly designated as ceramers due to the combination of the properties of ceramics (high modulus, thermal stability and low coefficient of thermal expansion) with those of organic polymers (high ductility, molecular flexibility and low temperature processing). These materials are often also known as phase-interconnected nanocomposites because of the high level of interconnection between the two phases with domain phase sizes approaching the nanometer scale. Ceramers have a huge potential for application in a variety of advanced technologies (Eckert, 2001; Sanchez, 2011; Kickelkick, 2006), both as structural materials and functional materials, such as catalyst supports, protective coatings (Messori, 2003, 2004a); Toselli, 2007; Fabbri, 2008), sensors (Rovati, 2011; Fabbri, 2011), and active glasses.

Optical fiber sensors are traditionally obtain by fully-inorganic sol-gel process that allows the creation of Si-O-Si linkages between the silica core of the optical fiber and the silica porous matrix deriving from the jellification of the sensitive dye-doped colloidal suspension (Cao, 2005). However, this approach cannot be easily applied in the case of plastic optical fibers, due to the ineffective interaction between the organic PMMA optical fiber core (Lin, 2000).

The approach proposed in this work consists in the fabrication of a $\mathrm{pH}$ sensor based on an organic-inorganic hybrid matrix obtained by a sol-gel process, doped with a $\mathrm{pH}$ sensitive indicator, to be applied at the tip of plastic optical fibers. Inside the sensitive element, the organic part of the hybrid glass, polyethylene oxide (PEO), plays a multiple role: (i) it allows good adhesion between the plastic optical fiber and the whole sensitive element; (ii) its weak hydrophilicity permits to tune the kinetic of response of the sensor by influencing the 
diffusion rate of the analyte inside the porous matrix and its interaction with the indicator; (iii) its nature of organic compound allows better physical and chemical interactions with the organic $\mathrm{pH}$ indicator dispersed in the hybrid matrix, thus reducing problems of leaching and enhancing the response rate of the sensor.

\subsection{Polymer-silica sol-gel hybrids for $\mathrm{pH}$ indicators entrapment}

Several studies have been performed on the preparation of $\mathrm{pH}$ sensors obtained by immobilization of a $\mathrm{pH}$ sensitive indicator onto the tip or onto the sides of traditional silica core optical fibers by means of the sol-gel technology (MacGraith, 1991; Gupta, 1998; Alvarado-Mendez, 2005; Rayss, 2002; Miled, 2002; Dong, 2008; Lee, 2001), thanks to the outstanding flexibility of this chemical technique. For this application, silica glass is usually prepared by sol-gel via hydrolysis and condensation reactions of the precursor tetraethylorthosilicate (TEOS), in the presence of water (to promote hydrolysis), ethanol (to enhance the miscibility of water and TEOS), and an acid or base catalyst. The resulting silica-based glass can be attached to the silica core of traditional optical fibers by uncladding of a portion of the optical fiber and activation of the silica core by immersion in nitric acid in order to form silanol groups onto the optical fiber surface, followed by deposition of the silica sol containing the $\mathrm{pH}$ indicator on the naked part of the optical fiber (Sharma, 2004). This procedure allows the creation of $\mathrm{Si}-\mathrm{O}-\mathrm{Si}$ linkages between the silica core of the optical fiber and the silica porous matrix deriving from gelification of the sensitive dye-doped colloidal suspension, thus achieving a permanent bonding between the sensitive element (sol-gel glass doped with indicator) and the optical fiber itself which will transmit the optical signal.

The nature of organic compound of the $\mathrm{pH}$ sensitive indicators can cause a scarce affinity with the inorganic silica matrix $(\mathrm{Wu}, 2006)$. This induces leaching out of the sensitive species from the support, and the only effective way to overcome this problem is to create covalent bonding or stabilizing interactions between the $\mathrm{pH}$ indicator and the embedding matrix; nevertheless, this approach demonstrated to strongly reduce the indicator's sensitivity because of the reduction of its mobility within the solid matrix, and to cause slow response.

If the same approach described above for the preparation of $\mathrm{pH}$ optical sensors applied to silica-core optical fibers would be applied to the new generation of plastic optical fibers, an ineffective interaction between the organic PMMA core and the inorganic silica sensitive element would be found, resulting in an unstable device with physical discontinuity between the optical fiber and the sensitive head applied onto its tip.

\subsection{Plastic optical fibers and sensing probe}

The developed sensor is based on a low-cost plastic optical fiber terminated with a sensing element. The sensing matrix takes advantage of the use of PEO/silica organic-inorganic hybrids obtained from sol-gel technique, and in particular of the weak hydrophilicity of PEO chains crosslinked by sol-gel reactions with TEOS. In the presence of aqueous solutions, the PEO domains can swell allowing a faster ion exchange with the surrounding solution. The extent of swelling depends on the PEO molecular weight and, in addition to the beneficial effect on ion diffusion rate, it leads to changes of the volume of the sensing element that can causes problems to the extraction of the $\mathrm{pH}$ information. A good balance of 
ion diffusion rate, adhesion to PMMA fibers and volume change was obtained using a PEO having a molecular weight 8000 . A schematic diagram of the probe configuration is reported in Fig. 1. Basic working principle is based on a classic colorimetric approach. The white interrogation light $\mathrm{I}_{\mathrm{i}}(\lambda)$ is scattered and absorbed by the sensing matrix that include a $\mathrm{pH}$ sensitive indicator (indicator). The change in color of this indicator induces a change in the optical spectrum of the outgoing light $\mathrm{I}_{\mathrm{o}}(\lambda, \mathrm{pH})$ collected by the fiber. Analyzing the spectrum of this optical signal the $\mathrm{pH}$ of the solution can be recovered.

Absorption operated by the indicator, which depends on the $\mathrm{pH}$ value of the solution, induces a change in the optical spectrum of the outgoing light collected by the fiber.

As the $\mathrm{pH}$ varies, the relative fractions concentrations of the dissociated [A-] and protonated $\left[\mathrm{HA}^{+}\right]$forms of the indicator are changed according to the Henderson-Hasselbalch equation:

$$
\begin{aligned}
{\left[H A^{+}\right] } & =\frac{C}{1+10^{p H-p K_{a}}} \\
{\left[A^{-}\right] } & =\frac{C}{1+10^{p K_{a}-p H}}
\end{aligned}
$$

where $\mathrm{Ka}$ is the acid dissociation constant, $\mathrm{pKa}$ is $-\operatorname{logKa}$, and $\mathrm{C}$ is the concentration of the indicator. According to Fig. 1, interrogation light $\mathrm{I}_{\mathrm{i}}(\lambda)$ is absorbed and scattered by the sensing matrix generating the outgoing light $\mathrm{I}_{\mathrm{o}}(\lambda, \mathrm{pH})$. According to the modified BeerLambert law, the spectrum of the outgoing light $\mathrm{I}_{\mathrm{o}}(\lambda, \mathrm{pH})$ can be estimated from the spectrum of the entering light $\mathrm{I}_{\mathrm{i}}(\lambda)$ (Splinter, 2006):

$$
\begin{gathered}
O D(\lambda, p H)=\log \frac{I_{i}(\lambda)}{I_{o}(\lambda, p H)}=\alpha_{A}(\lambda) \cdot d(\lambda, p H) \cdot\left[A^{-}\right]+\alpha_{H A}(\lambda) \cdot d(\lambda, p H) \cdot\left[H A^{+}\right]+G \\
O D(\lambda, p H)=C \cdot d(\lambda, p H) \cdot\left\{\frac{\alpha_{A}(\lambda)}{1+10^{p K_{a}-p H}}+\frac{\alpha_{H A}(\lambda)}{1+10^{p H-p K_{a}}}\right\}+G
\end{gathered}
$$

where $\operatorname{OD}(\lambda, \mathrm{pH})$ is the optical density, $\mathrm{a}_{\mathrm{A}}(\lambda)$ and $\mathrm{a}_{\mathrm{HA}}(\lambda)$ the specific extinction coefficients of the two forms, $\mathrm{d}(\lambda, \mathrm{pH})$ the mean optical path of the photons through the probe, and $\mathrm{G}$ a parameter related to the "geometry" of the probe. Hence, we consider the relative variations of the outgoing light as the sensor response:

$$
\begin{gathered}
\Re(\lambda, p H)=\frac{I_{0}\left(\lambda, p H_{r e f}\right)-I_{0}(\lambda, p H)}{I_{0}(\lambda, p H)}=-\frac{\Delta I_{0}(\lambda, p H)}{I_{0}(\lambda, p H)}=\frac{\Delta O D(\lambda, p H)}{\log (e)} \\
\Re(\lambda, p H)=\frac{C \cdot d(\lambda, p H)}{\log (e)} \cdot\left\{\frac{\alpha_{A}(\lambda)}{1+10^{p K_{a}-p H}}+\frac{\alpha_{H A}(\lambda)}{1+10^{p H-p K_{a}}}\right\}-B l\left(\lambda, p H_{\text {ref }}\right)
\end{gathered}
$$

where baseline $\mathrm{Bl}$ is

$$
B l(\lambda, p H)=\frac{C \cdot d\left(\lambda, p H_{r e f}\right)}{\log (e)} \cdot\left\{\frac{\alpha_{A}(\lambda)}{1+10^{p K_{a}-p H_{r e f}}}+\frac{\alpha_{H A}(\lambda)}{1+10^{p H_{r e f}-p K_{a}}}\right\}
$$

and $\mathrm{pH}_{\text {ref }}$ is the reference value of $\mathrm{pH}$ that annuls response $\mathfrak{R}(\lambda, p H)$. 


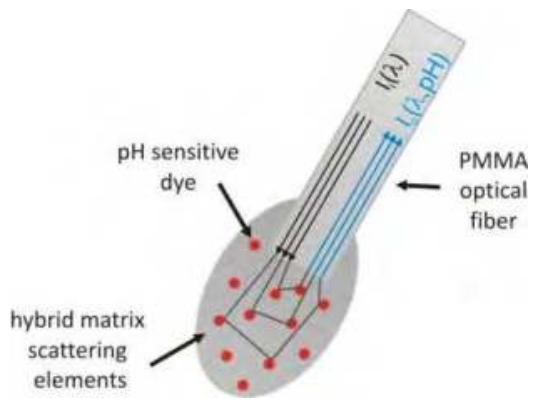

Fig. 1. Drawing of the probe configuration: $I_{i}(\lambda)$ is the interrogation light absorbed and scattered by the sensing hybrid matrix; $I_{0}(\lambda, p H)$ is the outgoing light containing the information of interest.

\section{Prototype sensors}

The developed sensor is based on a low-cost plastic (PMMA) optical fiber (Fort Fibre Ottiche, Italy) with core diameter $1 \mathrm{~mm}$ and numerical aperture 0.22 . The total length of the taken optical fiber is $35 \mathrm{~cm}$. The $\mathrm{pH}$ sensitive indicator (phenol red) was immobilized on the tip of the optical fiber taking advantage of the use of PEO to make hybrid gels. In the next sections the details about the prototype preparation are provided.

\subsection{Chemicals}

a, $\omega$-Hydroxy-terminated poly(ethylene oxide) (PEO; purchased by Fluka, Milan, Italy) having a number-average molecular weight of $8000 \mathrm{~g} / \mathrm{mol}$, 3isocyanatopropyltriethoxysilane (ICPTES; Fluka, Milan, Italy), tetraethylorthosilicate (TEOS; Aldrich, Milan, Italy), hydrochloric acid at a 37\% concentration ( $\mathrm{HCl}$, Carlo Erba, Milan, Italy), and ethanol (EtOH; Carlo Erba, Milan, Italy) were high-purity reagents and were used as received without further purification. Phenol red (PR; Aldrich, Milan, Italy) was used as received as $\mathrm{pH}$-sensitive indicator. $\alpha, \omega$-Triethoxysilane-terminated poly(ethylene oxide) (called PEOSi in the following) was prepared by the bulk reaction of the corresponding $\alpha, \omega-$ hydroxy-terminated poly(ethylene oxide) with ICPTES (molar ratio of 1:2). The reaction was carried out in a $50 \mathrm{~mL}$ glass flask equipped with a calcium chloride trap and under magnetic stirring at $120^{\circ} \mathrm{C}$ for $3 \mathrm{~h}$, following a reported procedure (Messori, 2004b).

\subsection{Preparation of the sensitive matrix}

$\mathrm{PEOSi} / \mathrm{SiO}_{2}$ hybrids were prepared by dissolving TEOS and PEOSi in EtOH at a concentration of about $60 \%(\mathrm{w} / \mathrm{v})$, and then adding water (for the hydrolysis reaction) and $\mathrm{HCl}$ in the following molar ratios with respect to the ethoxide groups of both the PEOSi and TEOS: $\mathrm{EtO}^{-} / \mathrm{H}_{2} \mathrm{O} / \mathrm{HCl} 1 / 1 / 0.05$. Then $\mathrm{pH}$ indicator $\mathrm{PR}$ was dissolved into the mixture (approx. $4 \mathrm{mg} / 50 \mathrm{~mL}$ ) and left under stirring at room temperature for $15 \mathrm{~min}$. The homogeneous indicator-doped mixture was finally heated at $60^{\circ} \mathrm{C}$ for $15-30 \mathrm{~min}$ (in order to approach the gel point) before application of a drop onto the tip of the optical fiber.

The hybrid material was characterized by final organic:inorganic weight ratio of $8: 2$ (assuming the completion of the sol-gel reactions). Samples were coded as follows: PEO-PR 
where PEO refers to the polymer phase within the hybrid and PR indicates the $\mathrm{pH}$ indicator entrapped in the hybrid.

\subsection{Preparation of the sensing probe}

The polymer-silica hybrid matrix, doped with $\mathrm{pH}$ indicator, was prepared as above reported; after the thermal treatment at $60{ }^{\circ} \mathrm{C}$ for $15-30 \mathrm{~min}$, condensation reactions involving ethoxysilane groups induced an increase in the viscosity of the solution, leading to a gel-like material. A drop of hybrid gel was then manually deposited onto the tip of the plastic optical fiber, and the optical fiber allowed to dry at atmospheric pressure and room temperature for $2 \mathrm{~h}$ and then cured at $105^{\circ} \mathrm{C}$ for $24 \mathrm{~h}$ to increase the extent of the sol-gel reaction and to induce a strong interfacial connectivity between the sensing matrix and the POF. The dimension of the hybrid sensitive element was optimized looking for the best compromise between the rate of the response of the optical sensor and its physical and mechanical robustness. The final appearance of the sensing probe is reported in Fig. 2.

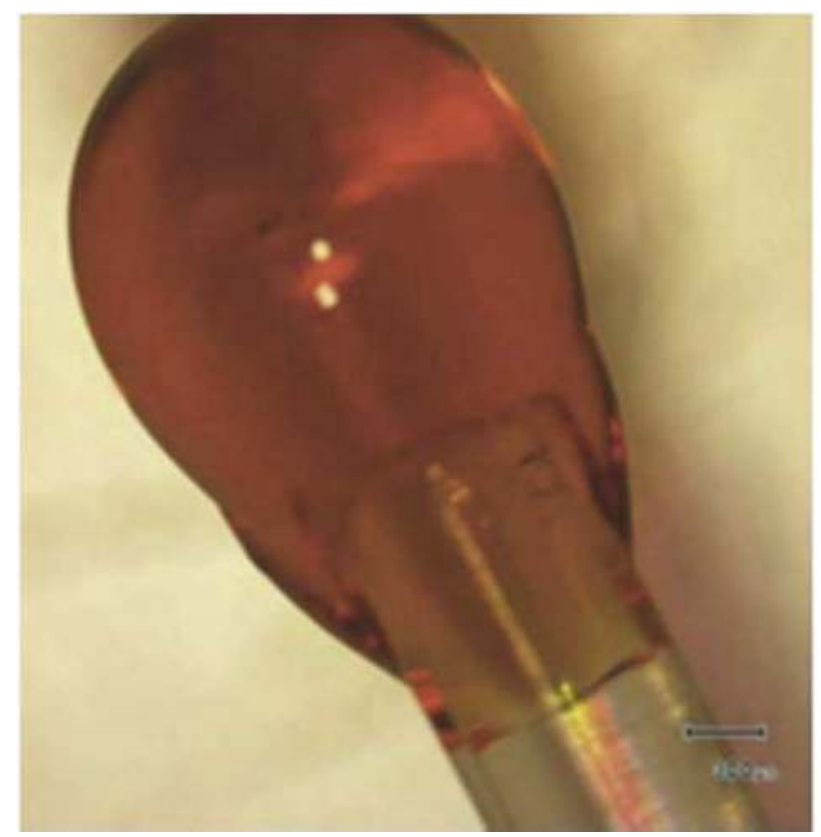

Fig. 2. Picture of the sensing probe: polymer-silica sol-gel hybrid deposited onto the tip of the POF.

\section{Instruments and methods}

In this section the instruments and methods used in the experimental activity are presented. To evaluate the performance of the developed probes a custom optical setup has been realized and characterized. Afterwards, ahead of the sensor characterization, the spectral properties of the sensing indicator have been determined. 


\subsection{Design and characterization of the optical setup}

The instrumental setup realized to interrogate the sensing probe is shown in Fig. 3. It performs the illumination of the tip of the optical fiber and the collection of the reflected beam.

It consists of a white light source WLS (tungsten halogen lamp, HL-2000-HF, Avantes, Netherlands), two fiber-optic collimators (PAF-SMA-5-550, OFR, USA), a cube beam splitter (039-1130, Optosigma, USA), a glass electrode pH-meter (Eutech Instrument, $\mathrm{pH} 700$ Netherlands) and a grating spectrometer OSA (PMA-11 C5966, Hamamatsu, Japan) equipped with a charge-coupled device detector. The beam, generated by the WLS, is delivered to the first collimator through a $0.5 \mathrm{~m}$ long multi-mode optical fiber $(1 \mathrm{~mm}$ core diameter, NA 0,51, Fort Fibre Ottiche, Italy). The beam splitter, fed by the collimated light, transmits the beam to the second collimator that re-focuses it into the optical fiber sensor, whose sensitive tip is submerged into the testing solution. The glass electrode $\mathrm{pH}$-meter monitors the testing solution.

The colored light reflected by the optical fiber sensor goes back over the optical fiber and reaches the entrance optical fiber bundle of the grating spectrometer OSA, after being deflected by the beam splitter. The measuring spectral range of our spectrometer covers the visible spectrum from 400 to $800 \mathrm{~nm}$. The maximum resolution achievable is $0.487 \mathrm{~nm}$; it has been computed dividing the spectral range by the number of acquisition spectral channels $(400 \mathrm{~nm} / 820 \mathrm{~nm})$. In fact, according to the Rayleigh criterion, which points out how wide the spectral distance between two lines must be to allow their recognition as separate lines, the spectral width of the individual lines must be markedly smaller than their spacing. The theoretical limit computed for our spectrometer does not take into account channels crosstalk and other non-idealities.

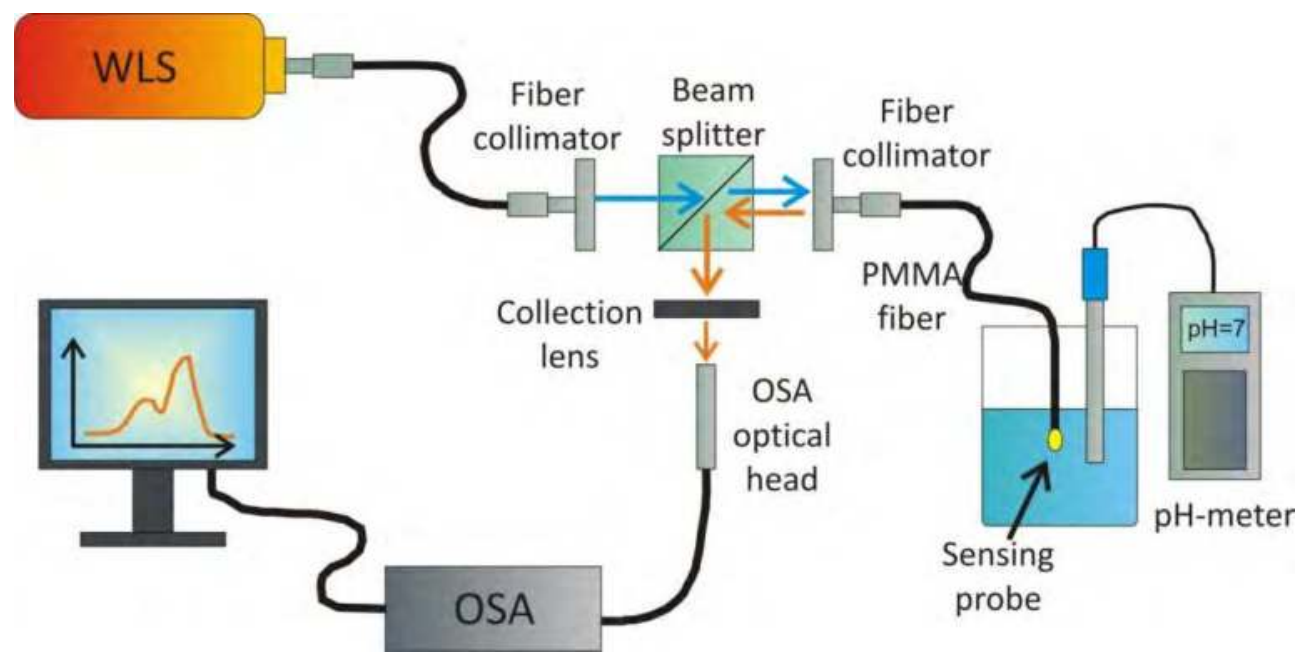

Fig. 3. Schematic design of the optical setup realized. WLS: tungsten halogen lamp, OSA: grating spectrometer.

In order to avoid the corruption of the spectral properties of the outgoing light because of the response of the measuring system and the transmission of the sensing POF, the spectral 
response of the interrogation system was measured using the experimental setup depicted in Fig. 4.

For this purpose, two measurements were performed; in particular, firstly, as shown in Fig. $4 \mathrm{a}$, the light spectrum at the output of a $35 \mathrm{~cm}$-long POF without sensing matrix was measured using spectrometer OSA. Afterwards, the spectrometer was reassembled as in Fig. $4 \mathrm{~b}$ using the same $35 \mathrm{~cm}$-long POF.

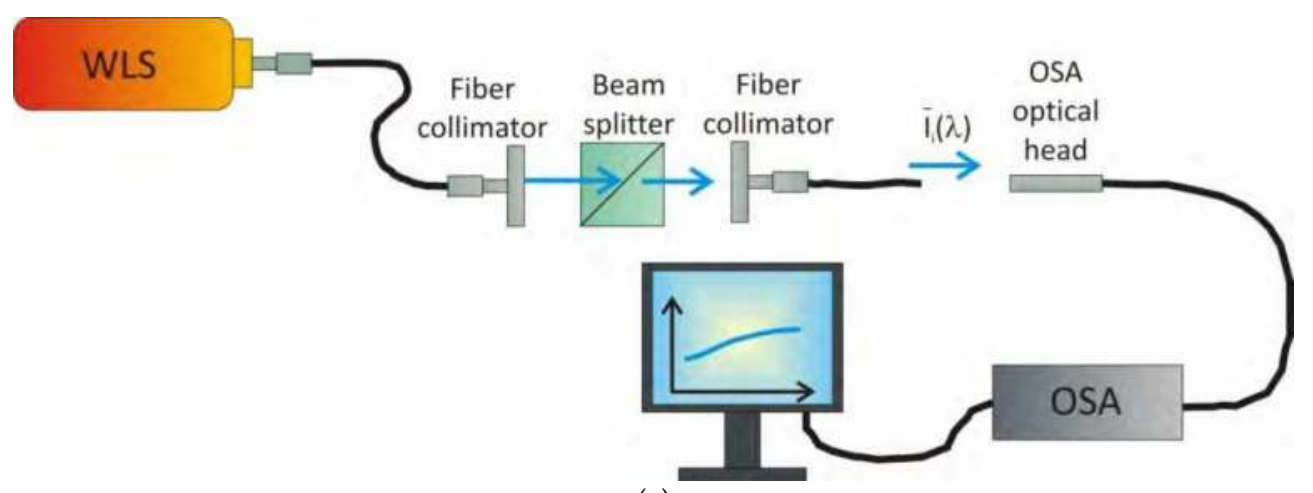

(a)

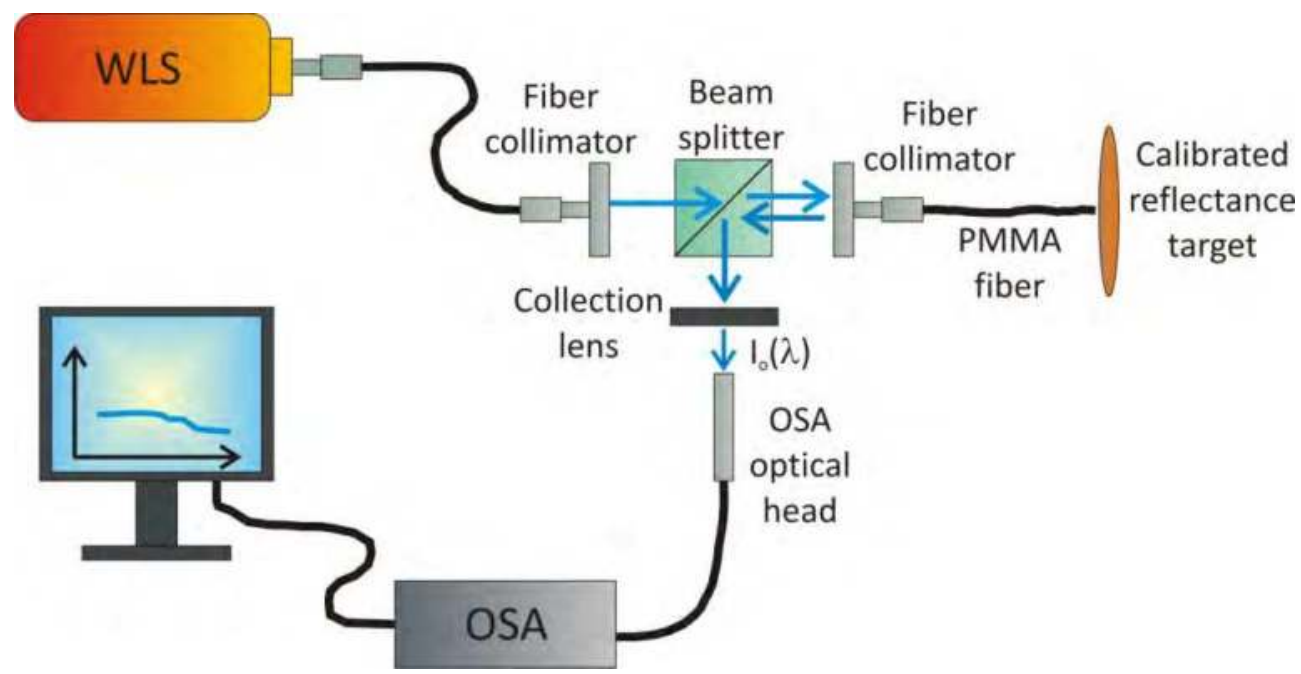

(b)

Fig. 4. Experimental setup used to measure the spectral response of the interrogation system. (a) The light spectrum at the output of a $35 \mathrm{~cm}$-long POF without sensing matrix was measured. (b) Afterwards, the spectrometer was reassembled and in front of the POF a calibrated reflectance target acted as a diffuser.

A NIST (National Institute of Standards and Technology) calibrated reflectance target ( $\mathfrak{I}=99 \%$, Labsphere, USA) acted as a lambertian diffuser in front of the POF. This target has 
a spectrally flat $( \pm 4 \%)$ reflectance over the UV-NIR spectrum. Spectrum $\mathrm{I}_{\mathrm{o}}(\lambda)$ acquired by OSA can be calculated as:

$$
I_{0}(\lambda)=k \cdot \mathfrak{J} \cdot S_{r}(\lambda) \cdot \tilde{I}_{i}(\lambda)
$$

where $\mathrm{k}$ is a coupling constant, $\mathfrak{I}$ the calibrated target reflectance assumed not dependent on the wavelength and $S_{r}(\lambda)$ the interrogation system response. Therefore, the ratio $\frac{I_{0}(\lambda)}{\tilde{I}_{i}(\lambda)}$ has been used to study the spectral trend of the interrogation system response.

In particular, the transmission features of the POF have been determined from the comparison between the spectrum of the halogen lamp WLS and $\tilde{I}_{i}(\lambda)$; as reported in literature (Feng, 2011), the POF exhibits an attenuation peak at about $750 \mathrm{~nm}$.

\subsection{Indicator optical characterization}

Subsequent to the characterization of the optical properties of the interrogation system, in this section we are going to report the optical measurements performed to determine the spectral properties of the sensing indicator.

The absorbance spectra of phenol red in distilled water at different $\mathrm{pH}$ values were measured using a commercial spectrometer (Lambda 19 Spectrometer, Perkin Elmer USA); thus the absorption values at $560 \mathrm{~nm}$ were normalized and fitted by the Boltzmann (sigmoidal) function according to Eq. (6).

$$
S=S_{0}-\frac{a}{1+e^{-\frac{p H-p K}{b}}}
$$

where $\mathrm{a}, \mathrm{b}$ and $\mathrm{S}_{0}$ are constants.

\subsection{Sensors characterization}

In our disposable sensor, the spectrum of the outgoing light $I_{0}(\lambda, p H)$ and thus the response of the sensor $\Re(\lambda, p H)$ is determined by two phenomena: the photon diffusion process in the hybrid-material drop applied to the optical fiber tip and the absorption of the indicator. Both these processes are $\mathrm{pH}$-dependent; indeed, the size of the hybrid drop depends on the $\mathrm{pH}$ level of the solution and so, varying the $\mathrm{pH}$, different photon optical paths are possible.

In order to characterize the sensing probe, measurements were performed at room temperature in standard $\mathrm{pH}$ buffers (Fisher Scientific) evaluating the response of the disposable sensor $\Re(\lambda, p H)$. According to the schematic representation in Fig. 5, the sensitive tip of the POF was immersed in $20 \mathrm{ml}$ of sample solution; measurements were taken at 5 min after changing the $\mathrm{pH}$ level, monitored with the reference $\mathrm{pH}$ meter, which has a measuring uncertainty of 0.05 units. The system response $\mathfrak{R}(\lambda, p H)$ was calculated acquiring a reference spectrum $I_{0}\left(\lambda, p H_{\text {ref }}\right)$ at $\mathrm{pH}_{\text {ref }}=10$ and varying the $\mathrm{pH}$ of the solution from 9 to 4 .

To evaluate the temporal response of the probe to a rapid change in $\mathrm{pH}$, the $\mathrm{pH}$ value of the solution has been staircase decreased from 8 to 5 with unitary steps of duration $10 \mathrm{~s}$ each. The same protocol has been applied for the reverse direction of the staircase, i.e. from 5 to 8 . Also during these measurements the testing solution was continuously monitored with the reference $\mathrm{pH}$ meter. The temporal response has been investigated firstly visually inspecting the color changes and then acquiring continuously the spectrum $I_{0}(\lambda, p H)$ and calculating $\mathfrak{R}(\lambda, p H)$ as a function of time. 

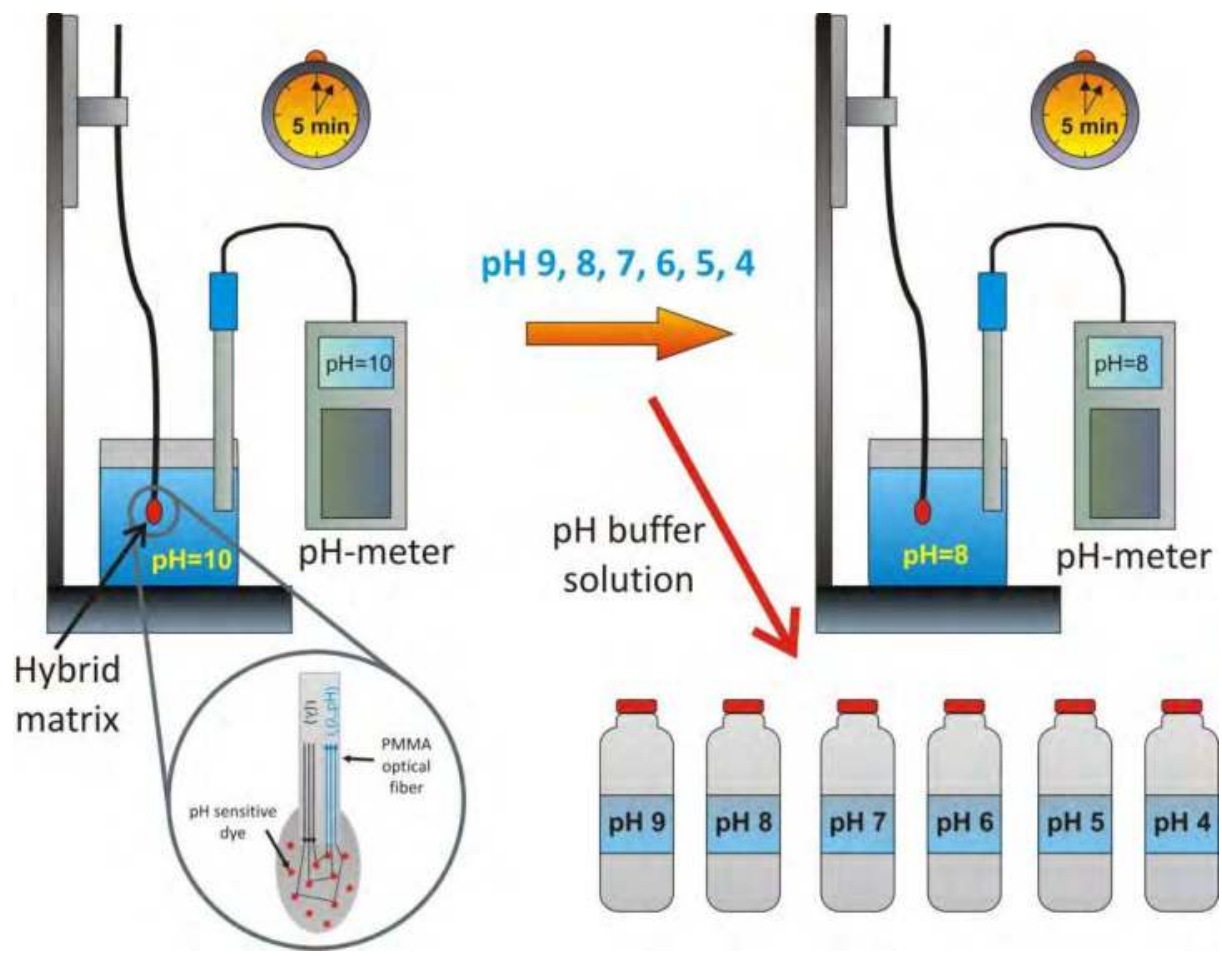

Fig. 5. Schematic representation of the measurement procedure. Firstly, a reference spectrum $I_{0}\left(\lambda, p H_{\text {ref }}\right)$ at $\mathrm{pH}_{\text {ref }}=10$ was acquired. Then, the $\mathrm{pH}$ has been changed from 9 to 4 , using standard $\mathrm{pH}$ buffers and the response of the disposable sensor has been taken at $5 \mathrm{~min}$ after changing the $\mathrm{pH}$ level, monitored with the reference $\mathrm{pH}$ meter.

\section{Results and discussion}

The optical properties of the interrogation system have been determined according to the measurement procedures reported in section 4.1. Spectra $I_{0}(\lambda), \tilde{I}_{i}(\lambda)$ and their ratio are shown in Fig. 6 together with the emission spectrum of the halogen lamp WLS. Other distortions of the halogen lamp spectrum are due to the transmission properties of the optical components used in the interrogation setup.

Figure $6 \mathrm{~b}$ shows the ratio $\frac{I_{0}(\lambda)}{\tilde{I}_{i}(\lambda)}$ that, according to Eq. (5), is proportional to the spectral response of the interrogation system. The spectral region of interest in our application is $500-600 \mathrm{~nm}$, i.e. green-yellow-red; since the response of the interrogation system is satisfactorily flat in this interval, as shown in Fig. 6b, the information of interest is not corrupted.

The spectral properties of the sensing indicator have been measured according to the procedure reported in section 4.2. The absorbance spectra of phenol red at different $\mathrm{pH}$ values are shown in Fig. 7; the maximum of all the spectra is well visible at the wavelength of about $560 \mathrm{~nm}$. According to literature (Wang, 2003), at this wavelength the phenol red 


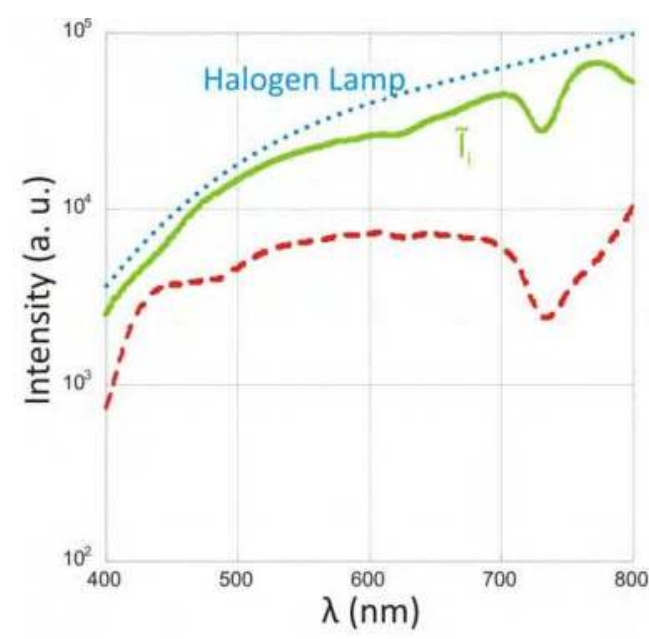

(a)

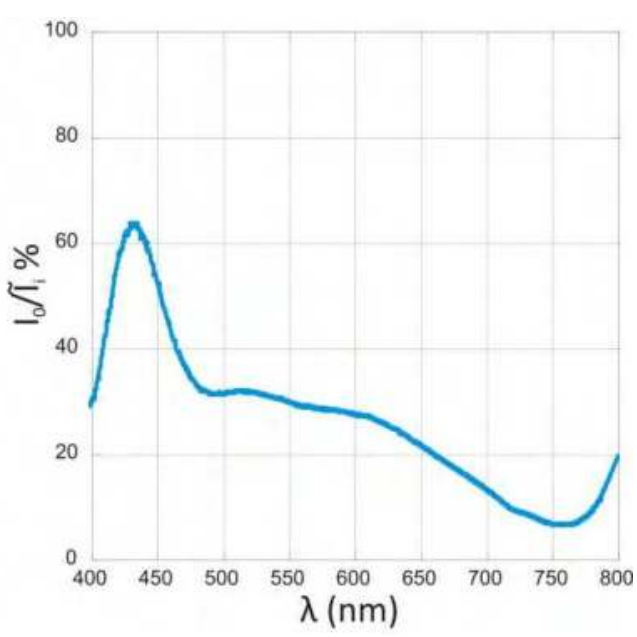

(b)

Fig. 6. Spectra of $\tilde{I}_{i}(\lambda)$ and $I_{o}(\lambda)(a)$, and spectral response of the interrogation system $(b)$. In (a), the upper dashed blue line represents the emission spectrum of the halogen lamp WLS. The spectral region of interest for our application is $500-600 \mathrm{~nm}$.

molecules exhibit a very low absorption that can be significantly enhanced by increasing the $\mathrm{pH}$ of the solution. Note that the absorbance at $560 \mathrm{~nm}$ showed a sharp transaction when the $\mathrm{pH}$ of the solution changed from 5 to 8 .

As shown in Fig. 8, the point of inflection (sigmoidal fitting function Eq. (6) equal to 0.5) corresponds to the apparent $\mathrm{pKa}$ value of 7.9. This value is in good agreement with the $\mathrm{pKa}$ of phenol red in aqueous solution reported in literature (Budavari, 1989).

The sensor characteristics have been measured according to the procedure reported in section 4.3. As shown in Fig. 9, a visual inspection of the probe at two different $\mathrm{pH}$ values of the solution underlines the swelling described in the previous sections. The spectra $\Delta I_{0}(\lambda, p H)=I_{0}(\lambda, p H)-I_{0}\left(\lambda, p H_{r e f}\right)$ acquired at different values of $\mathrm{pH}$ are shown in Fig. 10.

Observing Fig. 10, it is clear that the swelling/shrinking processes induce a change in the amplitude of the whole spectrum. As far as these phenomena are concerned, parameters $A$ and $S$ were considered to quantify the response of the sensor. In particular, as shown in Fig. 11, given a typical spectrum $\Delta I_{0}(\lambda)$, parameter $A$ and $S$ were calculated as follow: (i) the two maxima $M_{1}=\left(\lambda_{1}, I_{1}\right), M_{2}=\left(\lambda_{2}, I_{2}\right)$ and the minimum $m=\left(\lambda_{3}, I_{3}\right)$ of $\Delta I_{0}(\lambda)$ have been calculated using a standard Matlab ${ }^{\odot}$ routine; (ii) the equation of the line joining $\mathrm{M}_{1}$ and $\mathrm{M}_{2}$ has been calculated as $L(\lambda)=\frac{I_{2}-I_{1}}{\lambda_{2}-\lambda_{1}}\left(\lambda-\lambda_{1}\right)$; (iii) $\mathrm{A}$ has been defined as $L\left(\lambda_{3}\right)-I_{3}$ and $S$ as $L\left(\lambda_{3}\right)$.

As shown in Fig. 11, parameter $S$ is correlated to the spectrum amplitude and thus to swelling/shrinking processes while $\mathrm{A}$ is strictly related to the absorption (at about $\lambda=560 \mathrm{~nm}$ ) performed by the indicator. In Fig. 12, parameters A and S were calculated for each spectrum acquired and the normalized results are plotted against $\mathrm{pH}$. 


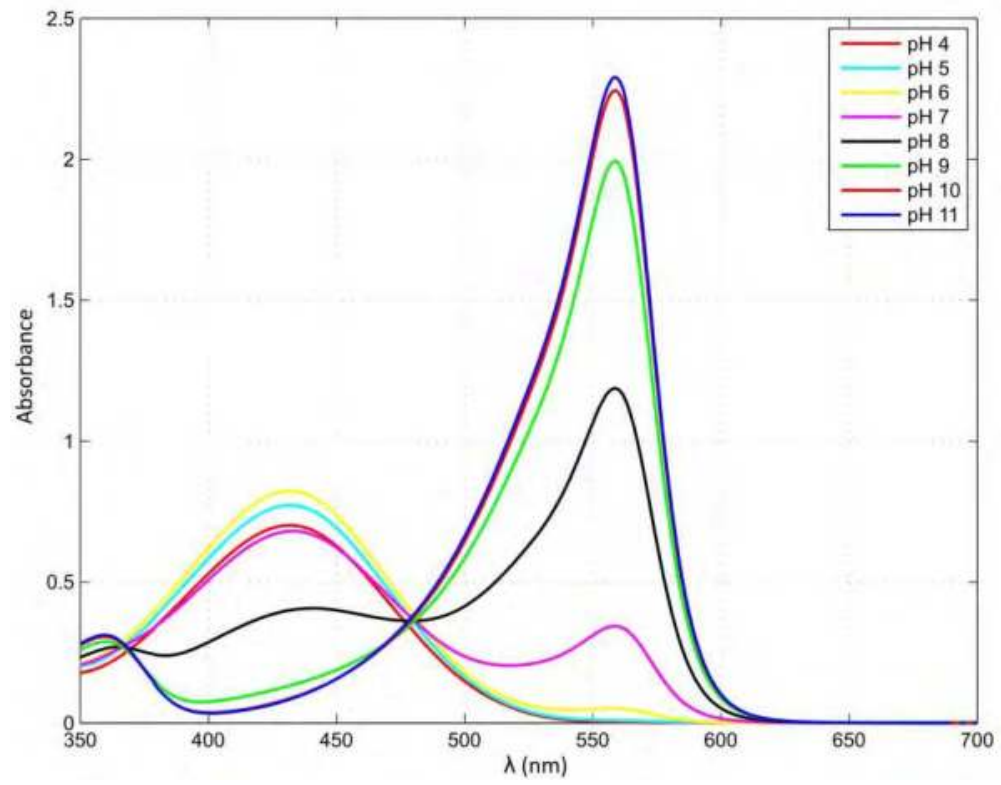

Fig. 7. Absorbance spectra of phenol red at different $\mathrm{pH}$ values.

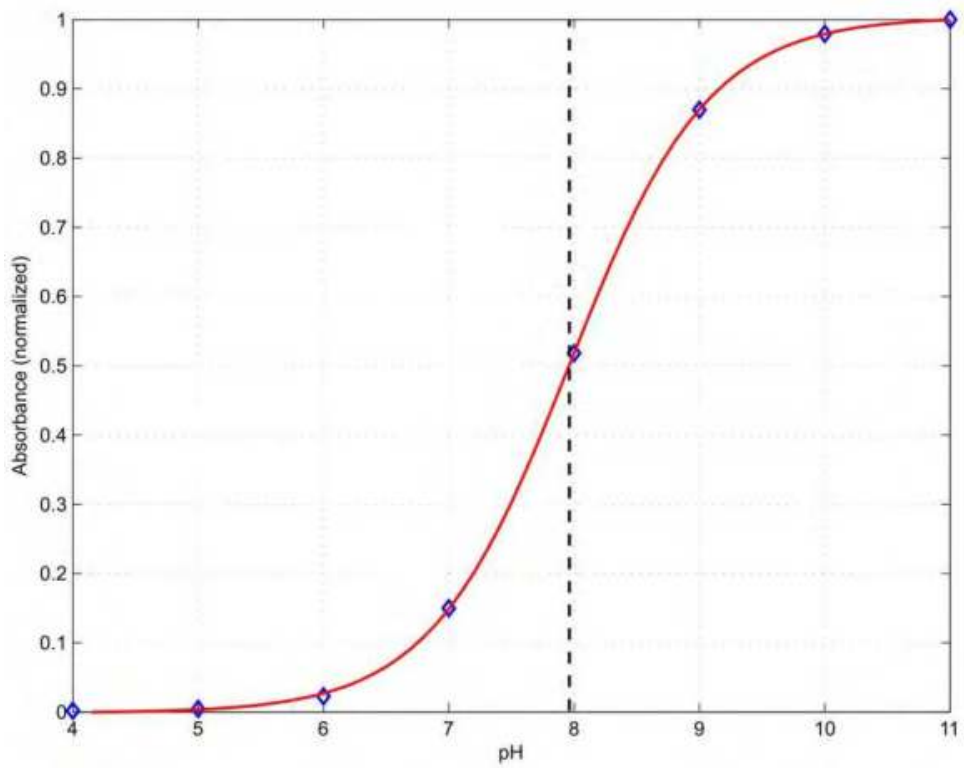

Fig. 8. Absorbance versus $\mathrm{pH}$ and Boltzmann interpolation function. 

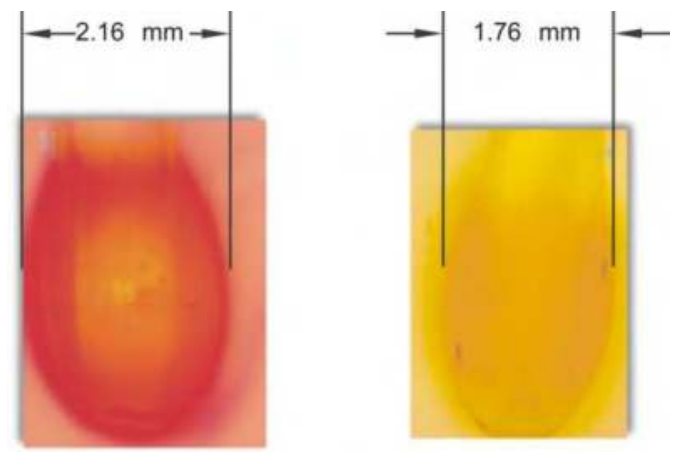

Fig. 9. Two shapes appearance of the probe PEO8000-8:2-PR after 5 min of immersion in basic (left) and acid (right) solution.

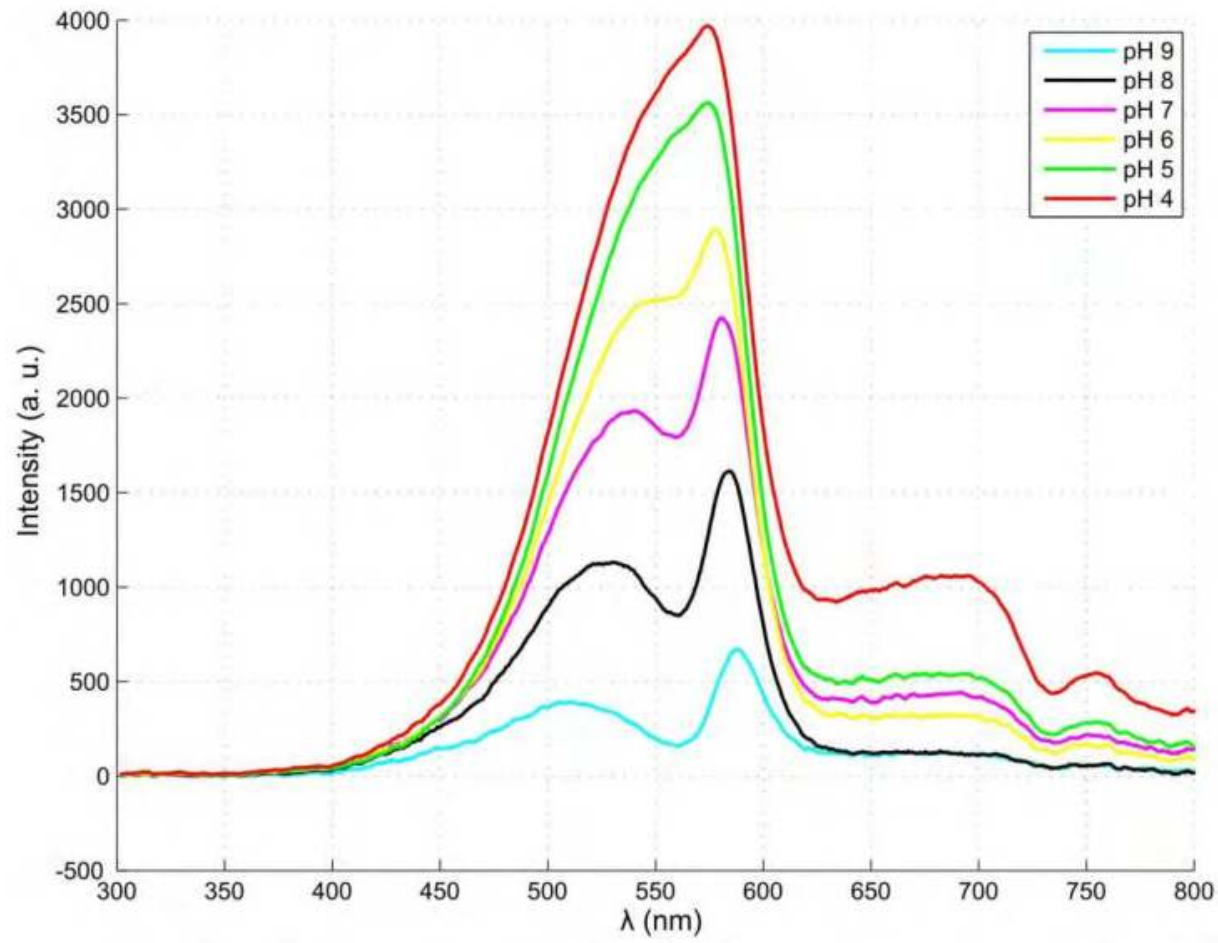

Fig. 10. Spectra of $\Delta I_{0}(\lambda)$ acquired at different values of $\mathrm{pH}$. The light absorption of phenol red is well visible at the wavelength of $560 \mathrm{~nm}$. Swelling/shrinking processes induce a change in the amplitude of the whole spectrum. 


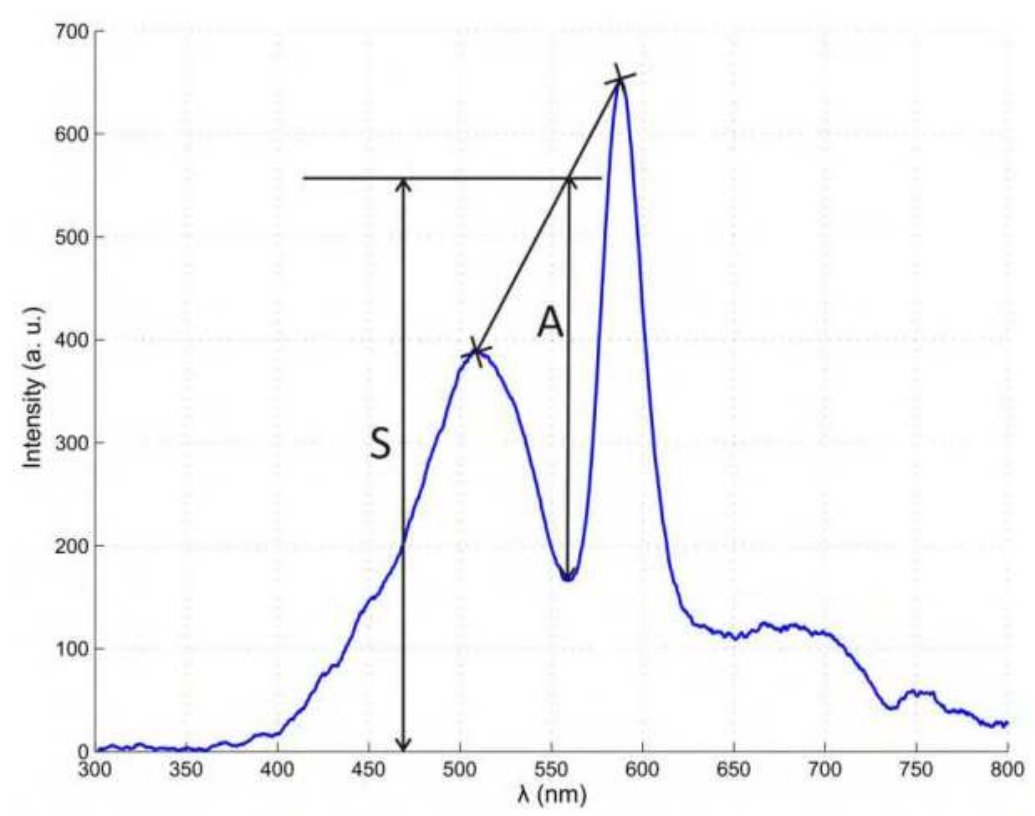

Fig. 11. Graphical definition of the two characteristic parameters. Parameter A is strictly related to the absorption performed by the indicator, whereas $S$ is correlated to the swelling/shrinking processes.

Parameter A exhibits a sharp transaction changing the $\mathrm{pH}$ of the solution from 5 to 8 . The experimental data was fitted by the Boltzmann (sigmoidal) function according to Eq. (6). The point of inflection (sigmoidal fitting function equal to 0.5) corresponds to the apparent $\mathrm{pKa}$ value $p K_{a}^{\prime}=6.8$. This value is lower than the measured value of $\mathrm{pKa}=7.9$ of phenol red in aqueous solution (Fig. 8). However, the pKa value can be shifted to lower $\mathrm{pH}$ with increasing ionic strength as observed by Holobar et al. (Holobar, 1993), and this phenomenon could occur also in our hybrid matrix.

An increase in the value of $\mathrm{pH}$ determines a higher swelling of the hybrid drop, as shown in Fig. 9, which leads to an increase in the distance between the optical fiber tip and the probeliquid interface and a consequent decrease in the mean optical path of the photons through the probe. As a consequence, according to Eq. (3), also the sensor response diminished. Coherently, as shown in Fig. 12b, parameter $S$ decreased linearly with the $\mathrm{pH}$ of the solution. The linear fit of the experimental data exhibits a slope of 0.17.

The response time of the probe PEO8000-8:2-PR was measured. A trade-off between the response time and the indicator leaching together with the adhesion between the sensitive matrix and the POF is required. In fact, high molecular weight PEO improves the adhesion and diminishes the indicator leaching, but causes long response time of the sensor. In general there are two different time constant; in fact, when $\mathrm{pH}$ is changed from 10 to 3 , the sensor was found to reach $90 \%$ of the regime signal intensity ( $\tau_{90}$ ) between 1 and 2 seconds, while changing the $\mathrm{pH}$ from a low value to a high one resulted in longer response times that can be quantify in the order of some minutes, i.e. the kinetics depends on the direction of the 


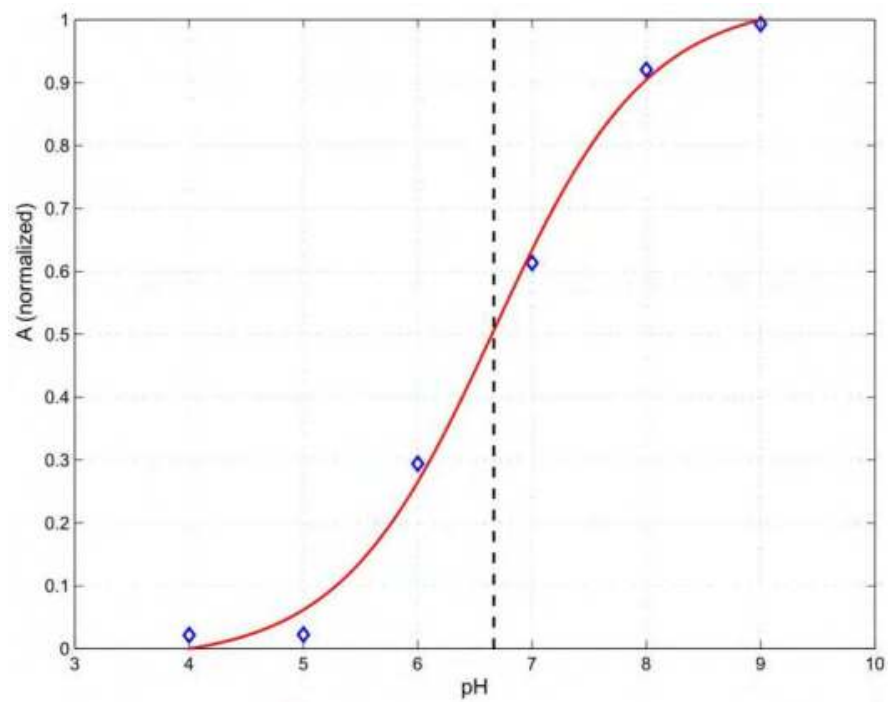

(a)

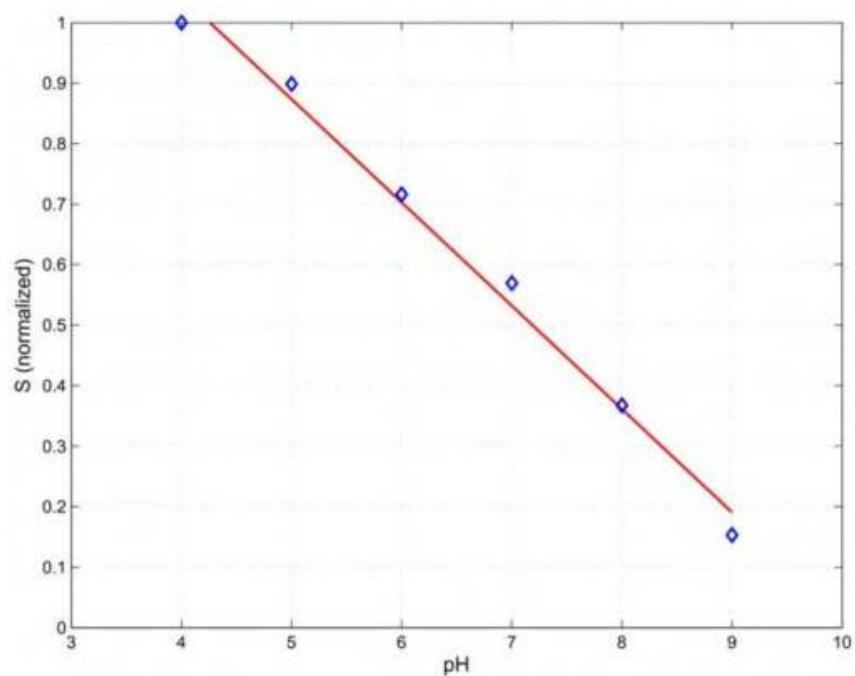

(b)

Fig. 12. Normalized $\mathrm{A}$ and $\mathrm{S}$ as a function of the $\mathrm{pH}$ value. Absorption parameter $\mathrm{A}$ is fitted by the Boltzmann function (a). Linear fit of the normalized $S$ exhibits a slope of 0.17 (b).

$\mathrm{pH}$ change (the $90 \%$ of the regime signal intensity was not reached in the time scale of the experiment, i.e. 10 seconds per step). This agrees with other experimental observations reported in literature (Ismail, 2002; Badini, 1995). Empirical quantification of this sensor behavior is shown in Fig. 13. 


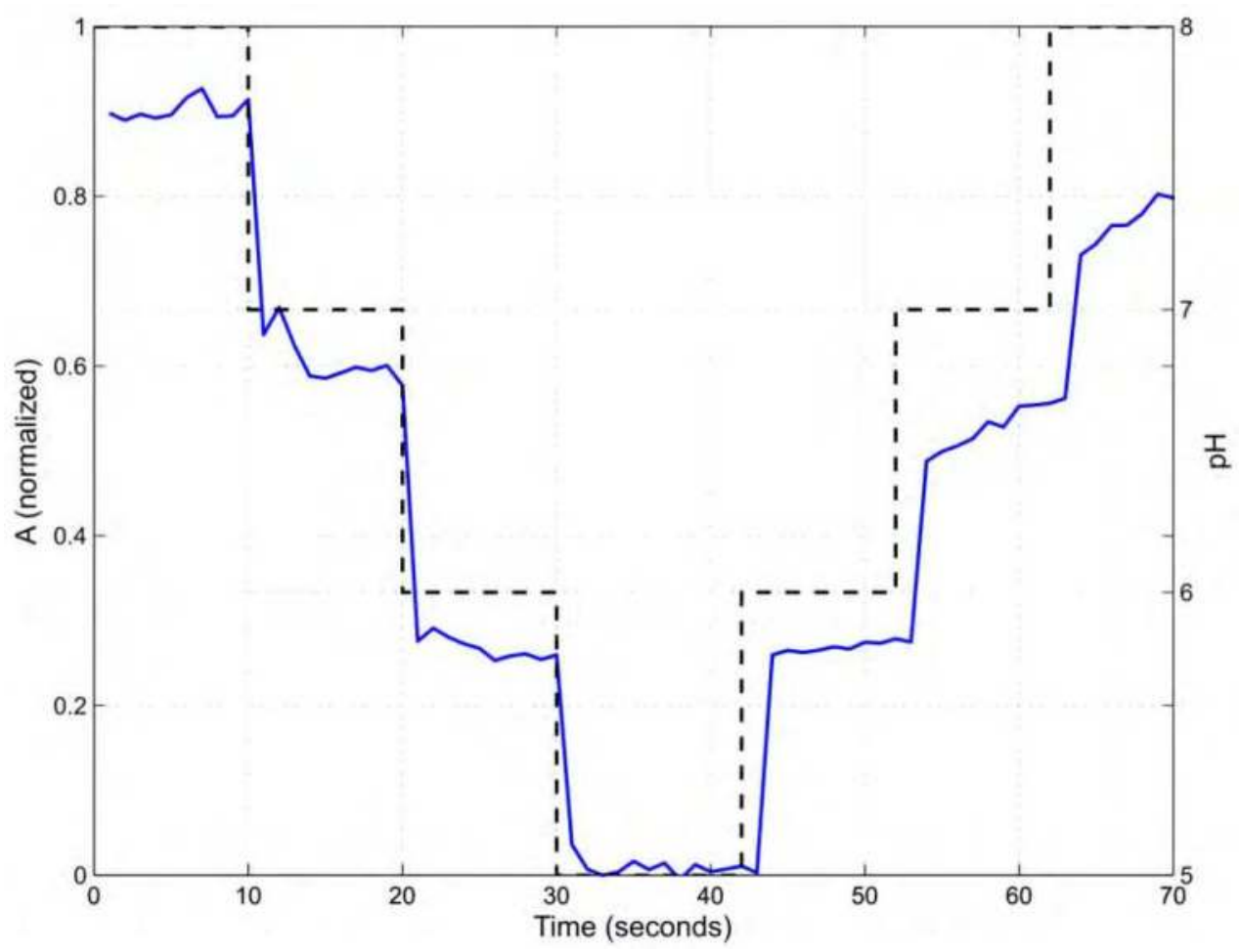

Fig. 13. Normalized A as a function of time for different values of $\mathrm{pH}$. The $\mathrm{pH}$ value of the solution has been staircase changed from 8 to 5 and then backs from 5 to 8 with unitary steps of duration $10 \mathrm{~s}$ each.

In Fig. 13, the parameter A (blue line) is represented as a function of time together with the value of the reference $\mathrm{pH}$ (dashed line).

We think that the slow response time observed changing the $\mathrm{pH}$ from 5 to 8 is strictly associated with the swelling/shrinking kinetics of the sensitive drop. Finally, the kinetics of swelling/shrinking has shown to be dependent on the direction of the $\mathrm{pH}$ change. This complex mechanism meddles in the photons propagation in the sensitive drop and thus in the response of the probe.

\section{Characteristics of the developed pH sensor}

The mean lifetime of disposable sensors, checked in the continuous mode operation at a $\mathrm{pH}$ level in the middle of the range, is two days. The reusability, tested with a series of probes checked once a day at a $\mathrm{pH}$ level in the middle of the range and preserved dry, has a mean life of one month. Table 1 shows these and other analytical parameters of the sensor. 


\begin{tabular}{|c|c|}
\hline Parameter & Value \\
\hline Optical interrogation wavelength & $560 \mathrm{~nm}$ \\
\hline Probe diameter & $2 \mathrm{~mm}$ (typ.) \\
\hline Measuring pH Range & $5-8$ \\
\hline Sensitivity & 0.5 a.u. $/ \mathrm{pH}$ unit (max.) \\
\hline Response time pH 8 to pH 5 & 4 min (typ.) \\
\hline Response time pH 5 to pH 8 & 1 month \\
\hline Reusability & 2 days \\
\hline Mean lifetime & less than 0.7 Euro \\
\hline Cost (few probes) &
\end{tabular}

Table 1. Characteristics of the developed disposable $\mathrm{pH}$ probe.

\section{Conclusions}

We present a disposable sensor based on a low-cost plastic optical fiber that covers an important $\mathrm{pH}$ range for physiological applications, e.g. in medicine and biotechnology, with excellent sensitivity. Some other advantages of the proposed sensor are: simple realization process, small size, high resistance to aggressive environments and electrical isolation.

The sensor characterization has been performed using a simple optical setup based on a single wavelength measurement. Nevertheless according to Lei (Lei, 2010), a ratiometric approach could improve the sensing overall performance. To this purpose, the isosbestic wavelength, i.e. $480 \mathrm{~nm}$, highlighted in the spectra shown in Fig. 7, could be conveniently exploited.

For practical applications, swelling/shrinking processes could make not trivial the extraction of the $\mathrm{pH}$ information and deteriorate the sensor response time. Nevertheless, this phenomenon can be practically cancelled minimizing the size of the sensing element. Large drop volume allows to make the probe fabrication simple and reproducible and to obtain high signal-to-noise ratio but emphasizes the swelling/shrinking effects. Depending on the application, the trade-off among these aspects can establish the optimal drop size.

\section{References}

Alvarado-Mendez E., Rojas-Laguna R., Andrade-Lucio J.A., Hernandez-Cruz D., Lessard R.A. \& Avina-Cervantes J.G., (2005). Design and characterization of $\mathrm{pH}$ sensor based on sol-gel silica layer on plastic optical fiber. Sens. Actuator B-Chem.: Vol. 106, pp. 518-522, ISSN 0925-4005

Aubonnet S., Barry H.F., von Bueltzingsloewen C., Sabbatie J.M. \& MacCraith B.D., (2003). Photo-patternable optical chemical sensors based on hybrid sol-gel materials. Electron. Lett., Vol.39, No.12, pp.913-914, ISSN 0013-5194

Bacci M., Baldini F.\& Bacci S. (1991). Spectroscopic behavior of acid-base indicators after immobilization on glass supports. Appl. Spectrosc., Vol.45, No.9, pp.1508-1515, ISSN 0003-7028

Badini G.E., Grattan K.T.V. \& Tseung A.C.C. (1995). Impregnation of a pH-sensitive dye into sol-gels for fibre optic chemical sensors. Analyst, Vol.120, No.4, pp. 1025-1028, ISSN 0003-2654 
Baldini F., Giannetti A., Mencaglia A.A. \& C. Trono. (2008). Fiber-optic sensors for biomedical applications. Curr. Anal. Chem., Vol.4, pp. 378-390; ISSN 1573-4110

Barnard S.M.\& Walt D.R. (1991). A fibre-optic chemical sensor with discrete sensing sites. Nature, Vol.353, pp. 338-340, ISSN 0028-0836

Bashir R., (2002), Micromechanical cantilever as an ultrasensitive pH microsensor. Appl. Phys. Lett. , 81, 3091-3093; ISSN 0003-6951

Ben-David O., Shafir E., Gilath I., Prior Y. \& Avnir D. (1997). Simple absorption optical fiber pH sensor based on doped sol-gel cladding material. Chem. Mat.,Vol.9, pp. 22552257, ISSN 0897-4756

Brinker C.J. \& Scherer G.W. (1990). Sol-gel science. The physics and chemistry of sol-gel processing. Academic Press, ISBN: 978-0121349707, New York

Bronk K. \& Walt D.R. (1994). Fabrication of patterned sensors arrays with aryl azides on a polymer-coated imaging optical fiber bundle. Anal. Chem, Vol.66, No.20, pp. 35193520, ISSN 1520-6882

Budavari S., O'Neil M.J., Smith A. \& Heckelman P.E. (1989). The Merck Index, 11th ed. Merck \& Co., ISBN: 0-911910-28-X, Inc. Rahway, NJ

Cagnol F., Grosso D. \& Sanchez C. (2004). A general one-pot process leading to highly functionalised ordered mesoporous silica films. Chem. Commun., pp. 1742-1743, ISSN 1359-7345

Cao W. \& Duan Y. (2005). Optical fiber-based evanescent ammonia sensor. Sens. Actuator BChem., Vol.110, No.2, pp. 252-259, ISSN 0925-4005

Cjlakovic M., Lobnik A. \& Werner T. (2002). Stability of new optical pH sensing material based on cross-linked poly(vinyl alcohol) copolymer. Anal. Chim. Acta, Vol.455, pp. 207-213, ISSN 0003-2670

de Marcos S. \& Wolfbeis O.S. (1996). Optical sensing of $\mathrm{pH}$ based on polypyrrole films. Anal. Chim. Acta, Vol.334, pp. 149-153, ISSN 0003-2670.

Dong S., Luo M., Peng G. \& Cheng W. (2008). Broad range pH sensor based on sol-gel entrapped indicators on fiber optic. Sens. Actuator B-Chem., Vol. 129, pp. 94-98, ISSN 0925-4005

Eckert H. \& Ward M. (Eds.). (2001) Nanostructured and functional hybrid organic-inorganic materials. Chem. Mat., Vol. 13, No. 10. ISSN 0897-4756

Estella J., Echeverria J.C., Laguna M. \& Julian J. (2007). Silica xerogels of tailored porosity as support matrix for optical chemical sensors. Simultaneous effect of $\mathrm{pH}$, ethanol:TEOS and water:TEOS molar ratios, and synthesis temperature on gelation time, and textural and structural properties. J. Non-Cryst. Solids, Vol.353, No.3, pp. 286-294, ISSN 0022-3093

Fabbri P., Leonelli C., Messori M., Pilati F., Toselli M., Veronesi, P., Morlat-Therias S., Rivaton A. \& Gardette J.L. (2008). Improvement of the surface properties of polycarbonate by organic-inorganic hybrid coatings. J. Appl. Polym. Sci., Vol. 108, No. 3, pp. 1426-1436. ISSN 0021-8995

Fabbri P., Pilati F., Rovati L., McKenzie R. \& Mijovic J. (2011). Poly(ethylene oxide)-silica hybrids entrapping sensitive dyes for biomedical optical sensors: molecular dynamics and optical response. Opt. Mater., 33(8), 1362-1369 ISSN 0925-3467

Feng C. \& Zhongyang R. (2011). Research on Measurement of POF Attenuation Spectrum. Intelligent Computation Technology and Automation (ICICTA), 2011 International Conference on, Vol.2, pp.672-674. 
Ferguson J.A., Healey B.G., Bronk K.S., Barnard S.M. \& Walt D.R. (1997). Simultaneous monitoring of $\mathrm{pH}, \mathrm{CO}_{2}$ and $\mathrm{O}_{2}$ using an optical imaging fiber. Anal. Chem, Vol.340, pp 123-131; ISSN 1520-6882

Fritz J., Baller M.K., Lang H.P., Strunz T., Meyer E., Guntherodt H.J., Delamarche E., Gerber Ch. \& Gimzewski J.K. (2000). Stress at the solid-liquid interface of self-assembled monolayers on gold investigated with a nanomechanical sensor. Langmuir, Vol.16, (November 2000), pp 9694-9696, ISSN 0743-7463

Goicoechea J., Zamarreno C.R., Matias I.R. \& Arregui F.J. (2009). Utilization of white light interferometry in $\mathrm{pH}$ sensing applications by mean of the fabrication of nanostructured cavities. Sens. Actuator B-Chem., Vol.B138, pp 613-618, ISSN 09254005

Grosso D., Cagnol F., Soler-Illia G.J., Crepaldi E.L., Amenitsch H., Brunet-Bruneau A., Bourgeois A. \& Sanchez C. (2004). Fundamentals of mesostructuring through evaporation-induced self-assembly. Adv. Funct. Mater. Vol.14, No.4, pp. 309-322, ISSN 1616-301X

Grummt U.W., Pron A., Zagorska M. \& Lefrant S. (1997). Polyaniline based optical pH sensor. Anal. Chim. Acta, Vol.357, pp. 253-259; ISSN 0003-2670

Gupta B.D. \& Sharma S. (1998). A long-range fiber optic $\mathrm{pH}$ sensor prepared by dye doped sol-gel immobilization technique. Opt. Commun., Vol. 154, pp. 282-284, ISSN 00304018

Healey B.G. \& Walt D.R. (1997). Fast temporal response fiber-optic chemical sensors based on the photodeposition of micrometer-scale polymer arrays. Anal. Chem, Vol.69, No.11, pp. 2213-2216; ISSN 1520-6882

Holobar A., Weigl B.H., Trettnak W., Benes R., Lehmann H., Rodriguez N.V., Wollschlager A., O'Leary P., Raspor P. \& Wolfbeis O.S. (1993). Experimental results on an optical $\mathrm{pH}$ measurement system for bioreactors. Sens. Actuator B-Chem., Vol.11, No.1-3, pp. 425-430, ISSN 0925-4005

Igarashi S., Kuvae K. \& Yotsuyanagi T. (1994). Optical pH sensor of electrostatically immobilized porphyrin on the surface of sulfonated-polystyrene. Anal. Sci., Vol.10, (October 1994), pp. 821-822, ISSN 0910-6340

Ismail F., Malins C. \& Goddard N.J. (2002). Alkali treatment of dye-doped sol-gel glass films for rapid optical pH sensing. Analyst, Vol.127, No.2, pp. 253-257, ISSN 0003-2654.

Kickelkick G. (2006). Hybrid materials. Synthesis, characterization, and application. Wiley$\mathrm{VCH}$, , ISBN 3527312994, New York

Korostynska O., Arshak K., Gill E. \& Arshak A. (2007), Review on state of the art in polymer based pH sensors. Sensors, Vol.7, pp 3027-3042, ISSN 1424-8220

Kowada Y., Ozeki T \& Minami T. (2005). Preparation of silica-gel film with $\mathrm{pH}$ indicators by the sol-gel method. J. Sol-Gel Sci. and Techn., Vol.33, pp. 175-185, ISSN 0928-0707

Lee S.T., Gin J., Nampoori V.P.N., Vallabhan C.P.G., Unnikrishnan N.V. \& Radhakrishnan P. (2001). A sensitive fiber optic $\mathrm{pH}$ sensor using multiple sol-gel coatings. J. Opt. APure Appl. Opt., Vol. 3, pp. 355-359, ISSN 1464-4258

Lei J., Wang L. \& Zhang J. (2010). Ratiometric pH sensor based on mesoporous silica nanoparticles and Förster resonance energy transfer. Chem. Commun., Vol. 46, pp 8445-8447, ISSN 1359-7345

Lin J. (2000). Recent development and applications of optical and fiber-optic pH sensors. Trends Anal. Chem., Vol.19, No. 9, pp 541-552, ISSN 0167-2940 
Lin J. \& Brown C.W. (1997). Sol-gel glass as a matrix for chemical and biochemical sensing. Trac-Trends Anal. Chem.Vol.16, No.4, pp. 200-211, ISSN 0167-2940

Lobnik A., Oehme I., Murkovic I. \& Wolfbeis O.S. (1998). pH optical sensors based on solgels: chemical doping versus covalent immobilization. Anal. Chim. Acta, Vol.367, pp. 159-165, ISSN 0003-2670

MacGraith B.D., Ruddy V., Potter C., O'Kelly B. \& McGilp J.F. (1991). Optical waveguide sensor using evanescent wave excitation of fluorescent dye in sol-gel glass. Electron. Lett., Vol. 27, pp. 1247-1248, ISSN 0013-5194

McDonagh C., Burke C.S. \& MacCraith B. D. (2008). Optical chemical sensors. Chem. Rev., Vol.108, pp. 400-422, ISSN 0009-2665

Messori M., Toselli M., Pilati F., Fabbri E., Fabbri P., Busoli S., Pasquali L. \& Nannarone S. (2003). Flame retarding poly(methyl methacrylate) with nanostructured organicinorganic hybrids coatings. Polymer, Vol. 44, No. 16, pp. 4463-4470, ISSN: 00323861

Messori M., Toselli M., Pilati F., Fabbri E., Fabbri P. \& Busoli S. (2004a). Poly(caprolactone)/silica organic-inorganic hybrids as protective coatings for poly(methyl methacrylate) substrates. Surf. Coat. Int., Vol. 86, No. 3, pp. 183-186, ISSN 1754-0925

Messori M., Toselli M., Pilati F., Fabbri E., Fabbri P., Pasquali L. \& Nannarone S. (2004b). Prevention of plasticizer leaching from PVC medical devices by using organicinorganic hybrid coatings. Polymer Vol. 45, pp. 805-813, ISSN 0032-3861

Miled O.B., H.B. Ouada \& J. Livage (2002). pH sensor based on a detection sol-gel layer onto optical fiber. Mater. Sci. Eng. C-Mater. Biol. Appl., Vol. 21, pp. 183-188, ISSN 09284931

Pringsheim E., Terpetschnig E. \& Wolfbeis O.S. (1997). Optical sensing of $\mathrm{pH}$ using thin films of substituted polyaniline. Anal. Chim. Acta, Vol.357, pp. 247-252, ISSN 00032670

Rayss J. \& Sudolski S. (2002). Ion adsorption in the porous sol-gel silica layer in the fiberoptic pH sensor. Sens. Actuator B-Chem., Vol. 87, pp. 397-405, ISSN 0925-4005

Rovati L., Fabbri P., Ferrari L. \& Pilati F. (2011). Construction and evaluation of a disposable $\mathrm{pH}$ sensor based on a large core plastic optical fiber. Rev. Sci. Instrum., Vol. 82, p. 023106, ISSN 0034-6748

Ruan C., Zeng K. \& Grimes C.A. (2003). A mass-sensitive pH sensor based on a stimuliresponsive polymer. Anal. Chim. Acta, Vol.497, pp 123-131, ISSN 0003-2670

Sanchez C., Shea K.J. \& Kitagawa S. (2011). Recent progress in hybrid materials science. Chem. Soc. Rev., Vol. 40, pp. 471-472, ISSN: 0306-0012

Schmidt H. (2000). Sol-gel derived nanoparticles as inorganic phases in polymer-type matrices. Macromol. Symp., Vol. 159, pp. 43-55, ISSN 1521-3900

Seki A., Katakura H., Kai T., Iga M. \& Watanabe K. (2007). A hetero-core structured fiber optic pH sensor. Anal. Chim. Acta, Vol 582, No.1, pp. 154-157, ISSN 0003-2670

Sharma N.K. \& Gupta B.D. (2004). Fabrication and characterization of a fiber-optic pH sensor for the $\mathrm{pH}$ range 2 to 13. Fiber Integrated Opt., Vol. 23, pp. 327-335 ISSN 0146-8030

Shi Y. \& Seliskar C.J. (1997). Optically transparent polyelectrolyte-silica composite materials: preparation, characterization, and application in optical chemical sensing. Chem. Mater., Vol.9, pp. 821-829, ISSN 0897-4756 
Song A., Parus S. \& Kopelman R. (1997). High-performance fiber-optic pH microsensors for practical physiological measurements using a dual-emission sensitive dye. Anal. Chem, Vol.69, No.5, (March 1997), p. 863867, ISSN 1520-6882

Sotomayor M.D.P.T., De Paoli M.A. \& Oliveira W.A.D. (1997). Fiber-optic pH sensor based on poly(o-methoxyaniline). Anal. Chim. Acta, Vol.353, pp 275-280, ISSN 0003-2670

Splinter R., Brett A. \& Hooper (2006). An introduction to biomedical optics. Taylor \& Francis Ed, ISBN: 07503093859780750309387, New York

Talaie A., Lee J.Y., Jang J., Romagnoli J.A. \& Taguchi T. (2000). Dynamic sensing using intelligent composite: an investigation to development of new $\mathrm{pH}$ sensors and electrocromic devices. Thin Solid Films, Vol. 363, pp. 163-166, ISSN 0040-6090

Toselli M., Marini M., Fabbri P., Messori M., \& Pilati F. (2007). Sol-gel derived hybrid coatings for the improvement of scratch resistance of polyethylene. : J. Sol-Gel Sci. Technol., Vol. 43, No. 1, pp. 73-83, ISSN 0928-0707

Wang E., Chow K.F., Kwan V., Chin T., Wong C. \& Bocarsly A. (2003). Fast and long term optical sensors for $\mathrm{pH}$ based on sol-gels. Anal. Chim. Acta, Vol. 495, No.1-2, pp. 4550, ISSN 0003-2670

Wen J. \& Wilkes G.L. (1996). Organic/inorganic hybrid network materials by the sol-gel approach. Chem. Mater., Vol.8, No.8, pp. 1667-1681, ISSN 0897-4756

Wolfbeis O.S. (2004). Fiber-optic chemical sensors and biosensors. Anal. Chem., Vol.76, No.12, pp. 3269-3284, ISSN 1520-6882

Wolfbeis O.S. (2008). Fiber-optic chemical sensors and biosensors. Anal. Chem., Vol.80, No.12, pp. 4269-4283, ISSN 1520-6882

Wu Z., Jiang Y., Xiang H., You L. (2006). Understanding the mechanisms of reaction and release of acid-base indicators entrapped in hybrid gels. J. Non-Cryst. Solids, Vol. 352, pp. 5498-5507, ISSN 0022-3093

Yuqing M., Jianrong C., \& Keming F. (2005). New technology for the detection of pH. J. Biochem. and Biophys. Methods, Vol.63, pp. 1-9, ISSN 0165-022X

Zamarreno C.R., Hernaez M., Del Villar I., Fernandez-Valdivielso C., Arregui F.J. \& Matias I.R. (2010). Optical fiber $\mathrm{pH}$ sensor fabrication by means of Indium tin oxide coated optical fiber refractometers. Phys. Status Solidi C: Current Topics in Solid State Phys., Vol.7, No. 11-12, pp. 2705-2707, ISSN 1862-6351

Zauner A., Bullock R., Di X. \& Young H.F. (1995). Brain oxygen, $\mathrm{CO}_{2}$, $\mathrm{pH}$ and temperature monitoring: evaluation in the feline brain. Neurosurgery, Vol.37, No.6, pp. 11761177, ISSN 0148-396X 


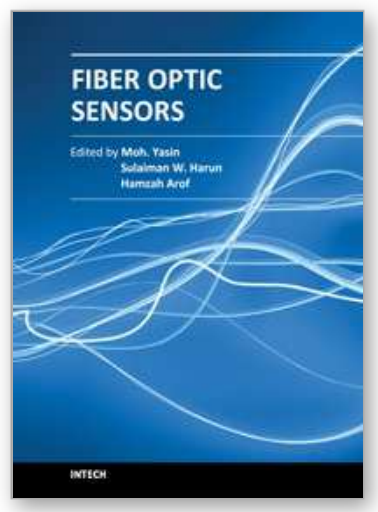

\author{
Fiber Optic Sensors \\ Edited by Dr Moh. Yasin
}

ISBN 978-953-307-922-6

Hard cover, 518 pages

Publisher InTech

Published online 22, February, 2012

Published in print edition February, 2012

This book presents a comprehensive account of recent advances and researches in fiber optic sensor technology. It consists of 21 chapters encompassing the recent progress in the subject, basic principles of various sensor types, their applications in structural health monitoring and the measurement of various physical, chemical and biological parameters. It also highlights the development of fiber optic sensors, their applications by providing various new methods for sensing and systems, and describing recent developments in fiber Bragg grating, tapered optical fiber, polymer optical fiber, long period fiber grating, reflectometry and interefometry based sensors. Edited by three scientists with a wide knowledge of the field and the community, the book brings together leading academics and practitioners in a comprehensive and incisive treatment of the subject. This is an essential reference for researchers working and teaching in optical fiber sensor technology, and for industrial users who need to be aware of current developments and new areas in optical fiber sensor devices.

\title{
How to reference
}

In order to correctly reference this scholarly work, feel free to copy and paste the following:

Luigi Rovati, Paola Fabbri, Luca Ferrari and Francesco Pilati (2012). Plastic Optical Fiber pH Sensor Using a Sol-Gel Sensing Matrix, Fiber Optic Sensors, Dr Moh. Yasin (Ed.), ISBN: 978-953-307-922-6, InTech, Available from: http://www.intechopen.com/books/fiber-optic-sensors/plastic-optical-fiber-ph-sensor-using-asol-gel-sensing-matrix

\section{INTECH}

open science | open minds

\section{InTech Europe}

University Campus STeP Ri

Slavka Krautzeka 83/A

51000 Rijeka, Croatia

Phone: +385 (51) 770447

Fax: +385 (51) 686166

www.intechopen.com

\section{InTech China}

Unit 405, Office Block, Hotel Equatorial Shanghai

No.65, Yan An Road (West), Shanghai, 200040, China

中国上海市延安西路 65 号上海国际贵都大饭店办公楼 405 单元

Phone: +86-21-62489820

Fax: $+86-21-62489821$ 
(C) 2012 The Author(s). Licensee IntechOpen. This is an open access article distributed under the terms of the Creative Commons Attribution 3.0 License, which permits unrestricted use, distribution, and reproduction in any medium, provided the original work is properly cited. 